\title{
Evaluation of the effect of wheat aleurone-rich foods on markers of antioxidant status, inflammation and endothelial function in apparently healthy men and women
}

\author{
Ruth K. Price ${ }^{1}$, Julie M. W. Wallace ${ }^{1}$, Lesley L. Hamill ${ }^{1}$, Edel M. Keaveney ${ }^{1}$, J. J. Strain ${ }^{1}$, \\ Michael J. Parker ${ }^{2}$ and Robert W. Welch ${ }^{1 *}$ \\ ${ }^{1}$ Northern Ireland Centre for Food and Health, University of Ulster, Coleraine BT52 1SA, UK \\ ${ }^{2}$ Northern Ireland Clinical Research Support Centre, Royal Group of Hospitals Trust, Belfast, UK
}

(Submitted 11 April 2011 - Final revision received 23 November 2011 - Accepted 28 November 2011 - First published online 16 January 2012)

\section{Abstract}

Observational data show an inverse association between the consumption of wholegrain foods, and inflammation and related diseases. Although the underlying mechanisms are unclear, wholegrains, and in particular the aleurone layer, contain a wide range of components with putative antioxidant and anti-inflammatory effects. We evaluated the effects of a diet high in wheat aleurone on plasma antioxidants status, markers of inflammation and endothelial function. In this parallel, participant-blinded intervention, seventy-nine healthy, older, overweight participants ( $45-65$ years, BMI $>25 \mathrm{~kg} / \mathrm{m}^{2}$ ) incorporated either aleurone-rich cereal products ( $27 \mathrm{~g}$ aleurone/d), or control products balanced for fibre and macronutrients, into their habitual diets for 4 weeks. Fasting blood samples were taken at baseline and on day 29. Results showed that, compared to control, consumption of aleurone-rich products provided substantial amounts of micronutrients and phytochemicals which may function as antioxidants. Additionally, incorporating these products into a habitual diet resulted in significantly lower plasma concentrations of the inflammatory marker, C-reactive protein $(P=0.035)$, which is an independent risk factor for CVD. However, no changes were observed in other markers of inflammation, antioxidant status or endothelial function. These results provide a possible mechanism underlying the beneficial effects of longer-term wholegrain intake. However, it is unclear whether this effect is owing to a specific component, or a combination of components in wheat aleurone.

\section{Key words: Aleurone: C-reactive protein: Inflammation: Wheat: Wholegrains}

Observational studies have consistently reported inverse relationships between wholegrain intake and diseases with an inflammatory aetiology, such as $\mathrm{CHD}^{(1)}$, diabetes ${ }^{(2)}$, cancer $^{(3)}$ and respiratory system disorders ${ }^{(4)}$. It is unclear how these effects are mediated, but the consumption of wholegrain cereals may exert anti-inflammatory effects and reduce oxidative stress. This is supported by data from cross-sectional studies, which show that markers of inflammation, including C-reactive protein (CRP), TNF- $\alpha$, plasminogen activator inhibitor- 1 and IL- 6 , are inversely related to wholegrain intake $e^{(5-9)}$

Nutritional interventions using foods or diets high in antioxidants are reported to lower plasma concentrations of inflammatory proteins, such as CRP, monocyte chemoattractant protein and IL- $1 \alpha$, and to decrease markers of endothelial function $^{(10,11)}$. Wholegrain products contain a wide array of antioxidants, and Fardet ${ }^{(12)}$ has identified over thirty compounds, or groups of compounds, including micronutrients and phytochemicals, which are known to function as antioxidants, at least in vitro. For example, tocols are direct radical scavengers that are present in wholegrain cereals mainly in the form of $\alpha$-tocopherol and $\beta$-tocotrienol, and in some wheat genotypes as $\gamma$-tocopherol ${ }^{(13)}$. $\mathrm{Zn}, \mathrm{Mn}, \mathrm{Cu}$ and Se are cofactors for antioxidant enzymes and are also present at relatively high concentrations in wholegrain cereals ${ }^{(14)}$. More recently, the anti-inflammatory properties of betaine have been proposed $^{(15,16)}$. Phenolic phytochemicals, and in particular ferulic acid, which have been closely associated with the in vitro antioxidant activity of grain fractions ${ }^{(17)}$ have direct freeradical-scavenging activities, as well as anticarcinogenic and anti-inflammatory properties ${ }^{(10,18)}$. In wheat grain, the most commonly consumed cereal in many countries, these components are found at the highest concentrations in the aleurone layer ${ }^{(19)}$, which also displays the greatest antioxidant capacity ${ }^{(17)}$. Wheat aleurone has relatively recently become available as a food ingredient through novel milling techniques ${ }^{(19)}$.

Thus, to evaluate wheat aleurone as a novel food ingredient, we carried out a controlled intervention study in

Abbreviations: CRP, C-reactive protein; FRAP, ferric-reducing antioxidant potential; RTE, ready-to-eat.

*Corresponding author: R. W. Welch, fax +44 287032 3023, email rw.welch@ulster.ac.uk 
apparently healthy men and women using products enriched with wheat aleurone to assess effects on plasma antioxidant status, inflammation and markers of endothelial function. However, despite the strong observational evidence for a relationship between wholegrain intake and inflammationrelated diseases, intervention studies in this area are limited, and the findings are inconsistent ${ }^{(20-24)}$. Consequently, although the primary aim was to assess the effects of wheat aleurone, this exploratory study may also provide insights into components and mechanisms underlying the longer-term effects of the increased consumption of wholegrain wheat.

\section{Methods \\ Participants}

A total of eighty apparently healthy participants, who were older ( $45-65$ years) and overweight $\left(\mathrm{BMI}>25 \mathrm{~kg} / \mathrm{m}^{2}\right)$, and thus at increased risk of the metabolic syndrome, were recruited from the Northern Ireland population using the following inclusion criteria: in general good health with no current or recent serious illness, no use of prescription medicine or vitamin or mineral supplements, non-smokers, without diagnosed diabetes, and not on a special diet. The study was conducted according to the guidelines laid down in the Declaration of Helsinki and all procedures involving human participants were approved by the University of Ulster Research Ethics Committee. Written informed consent was obtained from all participants, and the study was registered on the Current Controlled Trials Register (ISRCTN93336504).

\section{Study design}

The study was a parallel, participant-blinded, placebo-controlled intervention trial. Participants were stratified by sex and age and randomly assigned to receive either aleurone-rich cereal products (aleurone group) or control cereal products (control group). During the 4 -week intervention, participants were asked to incorporate one portion of ready-to-eat (RTE) cereal and two bread roll portions per day into their habitual diet. Cereal products were supplied weekly, and compliance was monitored by self-reported records and by the collection of unused or empty packets at the end of each week. Fasting venous blood samples and weight, and waist/hip measurements were taken at baseline and post-intervention ( 4 weeks). Waist circumference was measured midway between the lowest rib and the top of the iliac crest; and hip circumference was measured as the maximal circumference about the buttocks. Dietary intakes were assessed with $4 \mathrm{~d}$ food diaries before (baseline) and during week 3 of the intervention; and energy, nutrient and fibre intakes estimated using dietary analysis software (Weighed Intake analysis Software Package for Windows, version 3.0; Tinuviel Software).

\section{Cereal products}

Aleurone-enriched bread (in the form of rolls) and extruded RTE cereal products were developed for use in this study.
Each cereal portion contained $9 \mathrm{~g}$ of aleurone (Bühler AG), resulting in a nominal dose of $27 \mathrm{~g}$ aleurone/d. The control bread and RTE cereal products were formulated with similar energy, macronutrient and fibre contents, and portion weights as their aleurone counterparts as previously described ${ }^{(25)}$. Products were analysed for $\mathrm{Zn}, \mathrm{Mn}$ and $\mathrm{Cu}$ by inductivelycoupled plasma atomic emission spectrometry ${ }^{(26)}$, for Se by inductively-coupled plasma-MS ${ }^{(27)}$, for betaine by $\mathrm{NMR}^{(28)}$, and for phenolic acids by HPLC-MS ${ }^{(29)}$ (Rothamsted Research). Tocols were measured using normal-phase HPLC with fluorescence detection ${ }^{(13)}$ (University of Helsinki, Finland), and total antioxidant potential was assessed using a modification ${ }^{(30)}$ of the ferric-reducing antioxidant potential (FRAP) assay $^{(31)}$

\section{Blood sampling and biochemical measurements}

Fasting blood was collected into serum separator pre-evacuated blood tubes for high-sensitivity-CRP and cholesterol analyses, lithium heparin-containing blood tubes for FRAP and ferulic acid analyses, and EDTA-containing pre-evacuated blood tubes for other analyses. Erythrocytes were prepared from a single EDTA-tube by washing in PBS for three cycles $\left(2500 \mathrm{~g} ; 15 \mathrm{~min} ; 4^{\circ} \mathrm{C}\right)$. All other samples were kept on ice until centrifugation $\left(3^{\circ} \mathrm{C}, 1000 \mathrm{~g}, 15 \mathrm{~min}\right)$, within $4 \mathrm{~h}$, and stored at $-70^{\circ} \mathrm{C}$ until analysis.

\section{Plasma antioxidant micronutrients}

Plasma samples were analysed for $\alpha$-tocopherol and $\gamma$ tocopherol by reversed-phase HPLC, as previously described by Thurnham et $a l .{ }^{(32)}$ with minor modifications. Briefly, lipids were extracted and samples reconstituted in amber vials with mobile phase ( $470 \mathrm{ml}$ acetonitrile; $470 \mathrm{ml}$ methanol; $120 \mathrm{ml}$ dichloromethane; $0 \cdot 1 \mathrm{~g}$ butylated hydroxytoluene) before analysis by HPLC using an isocratic pump (model 1515), an autosampler (model 717), a Sunfire C18 $3.5 \mu \mathrm{m}$, $4.6 \times 100 \mathrm{~mm}$ column and photodiode array detector (model 2996; Waters Limited). The flow rate was $1.5 \mathrm{ml} / \mathrm{min}$, the run-time was $13 \mathrm{~min}$, and peaks were detected at $292 \mathrm{~nm}$. The method was validated using standard reference material (SRM 968c, NIST) and $\alpha$-tocopherol acetate (Sigma-Aldrich) was the internal standard. Data acquisition and processing were with Empower $2^{\mathrm{TM}}$ software (Waters Corporation). Intra-assay $\mathrm{CV}$ were $<7 \%$ and $<25 \%$, and inter-assay $\mathrm{CV}$ were $<7 \%$ and $<18 \%$ for $\alpha$ - and $\gamma$-tocopherol, respectively.

Plasma samples were analysed for $\mathrm{Se}, \mathrm{Cu}$ and $\mathrm{Zn}$, using inductively-coupled plasma-MS (XSeries I; Thermo Fisher Scientific), with collision cell technology mode for sample analysis; radio frequency power: $1340 \mathrm{~W}$; nebuliser gas flow: 0.88-0.94 litres/min; auxiliary gas flow: 0.7 litres $/ \mathrm{min}$; cool gas flow: 13 litres/min, collision cell technology gas flow ( $8 \% \mathrm{H}_{2} / \mathrm{He}$ ): $4 \mathrm{ml} / \mathrm{min}$; plasma source: $99.9 \%$ argon (BOC Limited); sample uptake rate: $0.4 \mathrm{ml} / \mathrm{min}$. Plasma samples were prepared with $2 \% \mathrm{HNO}_{3}$ (1:50), and calibration curves were prepared daily using pooled fasting plasma samples and a mixed standard. The method was validated using a standard reference serum (UTAK Laboratories, Inc.) with gallium 
nitrate (Romil Limited) as the internal standard. PlasmaLab software (Thermo Fisher Scientific) was used for data acquisition and processing. Intra-assay $\mathrm{CV}$ were less than 8,5 and 6\%, and inter-assay CV were less than 5, 4 and 5\% for Se, $\mathrm{Cu}$ and $\mathrm{Zn}$, respectively, and regression coefficients of all standard curves were $\geq 0.999$.

\section{Plasma ferulic acid}

Ferulic acid was analysed using a modification of the method of Matsui et al. ${ }^{(33)}$. Briefly, plasma samples $(80 \mu \mathrm{l})$ were prepared with starting mobile phase $(20 \mu \mathrm{l})$, followed by enzymatic deconjugation ${ }^{(34)}$. Samples were analysed by LC-MS/ MS (HPLC system (model 1200, Agilent Technologies), coupled to a triple quadrupole mass spectrometer (API-4000, Applied Biosystems) with ion spray source, using a Zorbax Eclipse XDB-C18 $2.130 \mathrm{~mm} \times 3.5 \mu \mathrm{m}$ column (Agilent Technologies) and mass detection by simultaneous ion monitoring mode with mass:charge ratio of parent and daughter ions 192.70 and $133.90 \mathrm{~m} / z$, respectively). The mobile phase was water-acetic acid (100:0.01, v/v; solvent A) and acetonitrile (100\%; solvent B) and were used in the LC gradient elution system based on the following gradient programme $(\mathrm{v} / \mathrm{v})$ : 0 min, $85 \%$ solvent A; 2 min, 5\% solvent A; $11 \mathrm{~min}, 85 \%$ solvent A; total run-time, $15 \mathrm{~min}$. Calibration curves were prepared daily using pooled fasting plasma samples spiked with trans-ferulic acid (Sigma-Aldrich). Data acquisition and processing were performed with Analyst software (V1.4, Applied Biosystems). The mean recovery of ferulic acid was $92 \%$ and CV for the intra- and inter-batch plasma controls were 2.9 and $5.3 \%$, respectively.

\section{Plasma antioxidant activity}

Total plasma antioxidant activity was measured using the FRAP assay ${ }^{(31)}$ modified for the Ilab 650 (Clinical Chemistry System; Instrumentation Laboratory). The mean CV for the intra- and inter-batch plasma controls were 0.7 and $4.2 \%$, respectively. Erythrocyte superoxide dismutase activity was analysed colorimetrically (Ransod; Randox Laboratories Limited) and expressed per g of erythrocyte $\mathrm{Hb}$. The CV for the intra- and inter-batch controls were 3.3 and $7 \cdot 8 \%$, respectively.

\section{Markers of inflammation and endothelial function}

Plasma IL-1 $\beta$, IL-6 and IL-10, TNF- $\alpha$ and monocyte chemoattractant protein 1 were measured with ELISA (R\&D Systems Europe Limited). CV for the intra- and inter-batch plasma controls, respectively, were IL-1 $\beta, 17 \cdot 1,12 \cdot 6 \%$; IL-6, 23.8, 12.6\%; IL-10, 11.9, 15.7\%; TNF- $\alpha, 7 \cdot 8,17 \cdot 1 \%$ and monocyte chemoattractant protein $1,5 \cdot 6,8.6 \%$. Serum CRP was measured by an ultra-sensitive colorimetric reaction (Quantex; Randox Laboratories Limited) modified for the Ilab 650, and the inter-batch $\mathrm{CV}$ for the plasma control was $2 \cdot 6 \%$. Plasma intracellular adhesion molecule- 1 and vascular cell adhesion molecule-1 were measured by ELISA (R\&D Systems Europe Limited) and $\mathrm{CV}$ for the intra- and inter-batch plasma controls, respectively, were intracellular adhesion molecule-1, 1·8, 3.5\%, and vascular cell adhesion molecule-1, 3·1, 6·2\%.

\section{Statistical analysis}

Post-intervention data (4 weeks) were compared using ANCOVA with baseline data as the covariate. Data with skewed distributions were transformed logarithmically before analyses. Independent $t$ tests were used to evaluate differences in reported compliance. All analyses were carried out using the Statistical Package for the Social Sciences 11.5 for Windows (SPSS, Inc.) and the data summarised using the means with their standard errors. Effects have been considered statistically significant when $P<0 \cdot 05$.

\section{Results}

\section{Participant characteristics and compliance}

Of the eighty participants, one female dropped out for medical reasons not related to the study, and seventy-nine participants completed the intervention (forty male; thirty-nine female, age 51.6 (SE 0.5) years, BMI 28.9 (SE 0.4) kg/m² ; waist: hip ratio $0.91(\operatorname{se} 0.01) \mathrm{cm})$. Reported compliance was high, with participants consuming 95.9 (SE 1.2) \% of the aleurone products and 96.3 (SE $1 \cdot 1$ ) $\%$ of the control products ( $P=0.774$ between groups). There was no effect of intervention on body weight or waist:hip ratio (data not presented).

Table 1. Characteristics of the cereal products (per portion)

\begin{tabular}{|c|c|c|c|c|}
\hline & \multicolumn{2}{|c|}{ Aleurone products } & \multicolumn{2}{|c|}{ Control products } \\
\hline & RTE cereal & Bread & RTE cereal & Bread \\
\hline Fresh weight $(\mathrm{g})$ & 40 & 67 & 39 & 67 \\
\hline Dry weight (g) & 39 & 42 & 38 & 43 \\
\hline \multicolumn{5}{|l|}{ Energy } \\
\hline $\mathrm{kJ}$ & 518 & 578 & 517 & 606 \\
\hline kcal & 124 & 138 & 124 & 145 \\
\hline Protein (g) & $5 \cdot 3$ & $7 \cdot 3$ & $5 \cdot 1$ & $7 \cdot 4$ \\
\hline Carbohydrate (g) & $26 \cdot 6$ & $22 \cdot 6$ & $26 \cdot 5$ & $24 \cdot 4$ \\
\hline Starch $(\mathrm{g})$ & $24 \cdot 8$ & $18 \cdot 6$ & $24 \cdot 8$ & $20 \cdot 4$ \\
\hline Sugars (g) & $1 \cdot 8$ & $4 \cdot 0$ & $1 \cdot 7$ & $4 \cdot 0$ \\
\hline Fat $(\mathrm{g})$ & 0.3 & $2 \cdot 7$ & 0.4 & $2 \cdot 7$ \\
\hline Fibre* $^{*}(g)$ & $5 \cdot 1$ & 6.5 & $5 \cdot 7$ & $6 \cdot 7$ \\
\hline Total tocols (mg) & 123 & 193 & 28 & 94 \\
\hline$\alpha$-Tocopherol (mg) & $0 \cdot 16$ & 0.71 & 0.14 & 0.57 \\
\hline$\gamma$-Tocopherol (mg) & 0 & 0.15 & 0 & 0.10 \\
\hline $\mathrm{Zn}(\mathrm{mg})$ & 1.65 & 1.80 & 0.38 & 0.58 \\
\hline $\mathrm{Mn}(\mathrm{mg})$ & $1 \cdot 39$ & $1 \cdot 48$ & 0.30 & 0.40 \\
\hline $\mathrm{Cu}(\mathrm{mg})$ & 0.27 & 0.29 & 0.07 & 0.10 \\
\hline Se $(\mu g)$ & 3.6 & $5 \cdot 6$ & $2 \cdot 3$ & 4.5 \\
\hline Betaine $(\mathrm{mg}) \dagger$ & 123 & 193 & 28 & 94 \\
\hline Total phenolics (mg) & $44 \cdot 6$ & $50 \cdot 0$ & $2 \cdot 7$ & 3.4 \\
\hline Total ferulic acid (mg) & $34 \cdot 8$ & $39 \cdot 6$ & $2 \cdot 0$ & 2.4 \\
\hline Free $(\mathrm{mg})$ & 0.17 & 0.68 & 0.04 & 0.13 \\
\hline Conjugated (mg) & 0.78 & 1.48 & 0.12 & 0.14 \\
\hline Bound (mg) & $33 \cdot 8$ & $37 \cdot 4$ & 1.85 & 2.09 \\
\hline $\begin{array}{l}\text { Antioxidant potentialł } \\
(\mu \text { mol FRAP) }\end{array}$ & 212 & 355 & 52 & 102 \\
\hline
\end{tabular}

RTE, ready-to-eat; FRAP, ferric-reducing antioxidant potential.

* Englyst method.

† Reported in Price et al. ${ }^{(25)}$

$\ddagger$ Ferric-reducing antioxidant potential. 


\section{Analyses of cereal products and dietary intakes}

The aleurone and control products were similar in macronutrient and fibre contents (Table 1). However, aleurone products were higher in antioxidant micronutrients and phytochemicals than their control counterparts (Table 1). The most abundant phenolic in the aleurone products was ferulic acid (approximately $79 \%$ of total phenolics present), which was mainly in the bound form (approximately 96\% of total ferulic acid present). Total antioxidant activity, as measured by FRAP, was $>3$ times higher in the aleurone products compared to the control products. From the compliance data, we estimated that mean micronutrient intakes from these products per day, for the aleurone and control groups, respectively, were: total tocols, $488 v$. $208 \mathrm{mg}$; Zn, 5.0 v. $1.5 \mathrm{mg} ; \mathrm{Cu}, 0.8$ v. $0.3 \mathrm{mg} ; \mathrm{Mn}, 4.3$ v. $1.1 \mathrm{mg}$; Se, 14.2 $v .10 \cdot 9 \mu \mathrm{g} ;$ and total phenolic acids, $139 v .9 \mathrm{mg}$ (ferulic acid, $109 v .7 \mathrm{mg}$ ).

Data from the $4 \mathrm{~d}$ food diaries at baseline and during the intervention are shown in Table 2. Overall, mean baseline daily intakes for vitamin $\mathrm{E}$ were 8.0 (SE 0.4 ; range $1 \cdot 8-20 \cdot 1) \mathrm{mg} / \mathrm{d} ; \mathrm{Zn}, 9.7(\mathrm{se} 0.3$; range $4.5-17 \cdot 8) \mathrm{mg} / \mathrm{d} ; \mathrm{Mn}$, 3.8 ( $\mathrm{SE} 0.2 ;$ range $1.4-10.3) \mathrm{mg} / \mathrm{d} ; \mathrm{Cu}, 1 \cdot 2$ (SE 0.1 ; range $0 \cdot 6-4.0) \mathrm{mg} / \mathrm{d}$; Se, 44.6 (SE $2 \cdot 2$; range $15-121) \mu \mathrm{g} / \mathrm{d}$; and during the intervention, these intakes were significantly higher in the aleurone group (Table 2). There were no significant differences in intakes of energy, fibre or macronutrients between the groups $(P>0 \cdot 121)$.

\section{Plasma antioxidant status}

The intervention had no significant effect on fasting plasma concentrations of tocols, Se, ferulic acid, FRAP and superoxide dismutase (Table 3). Furthermore, there were no significant effects on fasting plasma concentrations of $\mathrm{Zn}$ or $\mathrm{Cu}$ (data not shown).

\section{Markers of inflammation and endothelial function}

Baseline plasma CRP concentrations ranged from 0.2 to $11.4 \mathrm{mg} / \mathrm{l}$, with thirteen participants classed as high risk for future cardiovascular events $(>3 \mathrm{mg} / \mathrm{l})^{(35)}$. Post-intervention, there was a significant difference in plasma CRP between the groups, with concentrations about 25\% lower in the aleurone group compared to the control group (effect size of intervention: $-1.06 \mathrm{mg} / \mathrm{l}$; Table 3 ). There were no significant differences between the aleurone and control groups for any of the other markers for inflammation or endothelial function that were measured (Table 3).

\section{Discussion}

Results from the present study showed that, compared to refined grain-based control products, aleurone-rich products provided substantially more micronutrients and phytochemical compounds which have antioxidant functions. Additionally, the incorporation of these products into a habitual diet was associated with a small, but significantly lower, fasting plasma concentration of the inflammatory marker CRP.

$\mathrm{CRP}$ is an independent risk factor for CHD in both the general population and in high-risk groups ${ }^{(36-38)}$. Furthermore, CRP is one of the most sensitive acute-phase reactants and, in the absence of new stimuli, concentrations remain stable over long periods, thus making CRP a stable, clinically relevant biomarker ${ }^{(39)}$. Thus, small changes in CRP, similar to the effect size found in the present intervention $(-1.06 \mathrm{mg} / \mathrm{l})$, may represent a lowering in the clinical risk of cardiovascular events. This is supported by data from epidemiological studies. For example, in the Reykjavik Study ${ }^{(40)}$, differences between the lower and upper tertiles of CRP $(<0.78 v$. $>2.0 \mathrm{mg} / \mathrm{l}$ ) were associated with a 1.45 -fold (95\% CI 1.25 , 1.68) increased risk of CHD. Moreover, in the Women's Health Study ${ }^{(41)}$, comparisons of the first $(<1.5 \mathrm{mg} / \mathrm{l})$ and

Table 2. Estimated daily intakes of energy and selected micronutrients at baseline and during intervention with aleurone and control cereal products*

(Mean values with their standard errors)

\begin{tabular}{|c|c|c|c|c|c|c|c|c|c|}
\hline & \multicolumn{4}{|c|}{ Aleurone group ( $n$ 39) } & \multicolumn{4}{|c|}{ Control group ( $n$ 40) } & \multirow[b]{2}{*}{$P+$ (ANCOVA) } \\
\hline & Baseline & SE & Intervention & SE & Baseline & $\mathrm{SE}$ & Intervention & SE & \\
\hline \multicolumn{10}{|l|}{ Energy } \\
\hline kcal & 2036 & 83 & 2044 & 78 & 2122 & 97 & 2074 & 92 & 0.51 \\
\hline $\mathrm{kJ}$ & 8520 & 347 & 8551 & 327 & 8878 & 408 & 8678 & 386 & \\
\hline Carbohydrate (g) & 243 & $12 \cdot 1$ & 240 & $10 \cdot 4$ & 249 & 11.4 & 246 & 9.5 & 0.92 \\
\hline Starch (g) & 139 & $5 \cdot 7$ & 142 & $6 \cdot 2$ & 140 & $6 \cdot 2$ & 144 & $5 \cdot 8$ & 0.90 \\
\hline Fat (g) & 80.4 & 4.4 & 79.5 & 3.9 & 85.2 & 4.5 & $75 \cdot 7$ & 4.9 & 0.13 \\
\hline Protein (g) & $83 \cdot 3$ & 3.8 & $90 \cdot 6$ & 3.4 & $87 \cdot 3$ & 4.0 & $92 \cdot 0$ & 3.6 & 0.82 \\
\hline Fibre $\neq(\mathrm{g})$ & $14 \cdot 0$ & 0.6 & $26 \cdot 8$ & 0.7 & $15 \cdot 5$ & 0.8 & $29 \cdot 4$ & 0.8 & 0.12 \\
\hline Vitamin E (mg) & $7 \cdot 7$ & 0.6 & $15 \cdot 0$ & 0.5 & 8.3 & 0.6 & $13 \cdot 2$ & 0.6 & 0.001 \\
\hline $\mathrm{Zn}(\mathrm{mg})$ & $9 \cdot 4$ & 0.5 & 11.5 & 3.0 & $10 \cdot 1$ & 0.4 & 9.5 & 0.4 & $<0.001$ \\
\hline $\mathrm{Mn}(\mathrm{mg})$ & 3.81 & 0.26 & $6 \cdot 38$ & 0.13 & 3.74 & 0.19 & 3.81 & 0.21 & $<0.001$ \\
\hline Cu§ (mg) & $1 \cdot 20$ & 0.10 & 1.49 & 0.07 & 1.23 & 0.09 & 1.18 & 0.07 & $<0.001$ \\
\hline Se $(\mu \mathrm{g})$ & 43.5 & 2.9 & $76 \cdot 2$ & $2 \cdot 4$ & 45.7 & 3.4 & $69 \cdot 4$ & 2.9 & 0.02 \\
\hline
\end{tabular}

* Estimated from $4 \mathrm{~d}$ food records.

†Between-group effects during intervention using baseline data as a covariate (ANCOVA).

$\ddagger$ Englyst method.

$\S$ Data not normally distributed. 
Table 3. Plasma measurements at baseline and after 4-week intervention with aleurone-rich or control cereal products (Mean values with their standard errors, $n$ 79)

\begin{tabular}{|c|c|c|c|c|c|c|c|c|c|}
\hline & \multicolumn{4}{|c|}{ Aleurone group ( $n$ 39) } & \multicolumn{4}{|c|}{ Control group ( $n$ 40) } & \multirow[b]{2}{*}{$P(\text { ANCOVA })^{*}$} \\
\hline & Baseline & $\mathrm{SE}$ & 4 weeks & SE & Baseline & SE & 4 weeks & SE & \\
\hline \multicolumn{10}{|l|}{ Antioxidant status } \\
\hline$\alpha$-Tocopherol† ( $\mu \mathrm{mol} / \mathrm{l})$ & $29 \cdot 1$ & 1.6 & 28.9 & $1 \cdot 7$ & $29 \cdot 3$ & 1.3 & 29.4 & $1 \cdot 1$ & 0.64 \\
\hline$\gamma$-Tocopherol $(\mu \mathrm{mol} / \mathrm{l})$ & 1.94 & 1.4 & 1.67 & 1.4 & 1.96 & $1 \cdot 1$ & 1.95 & $1 \cdot 1$ & 0.06 \\
\hline $\operatorname{Se}(\mu \mathrm{g} / \mathrm{l})$ & $76 \cdot 8$ & 1.9 & $79 \cdot 0$ & 1.7 & 82.5 & 1.4 & 83.4 & 1.5 & 0.70 \\
\hline Ferulic acid† $(\mu \mathrm{mol} / \mathrm{l})$ & $98 \cdot 0$ & 4.3 & $97 \cdot 2$ & $3 \cdot 0$ & 101.4 & $6 \cdot 0$ & $106 \cdot 3$ & $7 \cdot 4$ & 0.52 \\
\hline FRAP $(\mu \mathrm{mol} / \mathrm{l})$ & 1149 & 40 & 1121 & $36 \cdot 2$ & 1180 & 37 & 1174 & 36 & 0.27 \\
\hline $\mathrm{SOD}(\mathrm{U} / \mathrm{g} \mathrm{Hb})$ & 1506 & 47 & 1499 & 42 & 1465 & 35 & 1450 & 32 & 0.68 \\
\hline \multicolumn{10}{|l|}{ Inflammatory markers } \\
\hline $\mathrm{IL}-1 \beta \dagger(\mathrm{pg} / \mathrm{ml})$ & 0.13 & 0.01 & 0.13 & 0.01 & 0.12 & 0.01 & $0 \cdot 12$ & 0.01 & 0.12 \\
\hline $\mathrm{IL}-6 \dagger(\mathrm{pg} / \mathrm{ml})$ & 1.70 & 0.45 & 1.49 & 0.35 & 1.22 & 0.11 & 1.58 & 0.30 & 0.16 \\
\hline $\mathrm{IL}-10 \dagger(\mathrm{pg} / \mathrm{ml})$ & $1 \cdot 17$ & 0.04 & 1.21 & 0.06 & 1.08 & 0.03 & 1.05 & 0.04 & $0 \cdot 16$ \\
\hline $\mathrm{CRP}+(\mathrm{mg} / \mathrm{l})$ & $2 \cdot 32$ & 0.42 & 1.94 & 0.34 & 1.74 & 0.20 & $2 \cdot 42$ & 0.39 & 0.035 \\
\hline TNF- $\alpha \dagger(p g / m l)$ & 1.72 & 0.09 & 1.66 & 0.08 & 1.47 & 0.06 & 1.42 & 0.05 & 0.30 \\
\hline MCP-1† (pg/ml) & 184 & 7 & 166 & 6 & 172 & 8 & 165 & 7 & 0.55 \\
\hline \multicolumn{10}{|l|}{ Endothelial function } \\
\hline ICAM-1 (ng/ml) & 210 & 10 & 210 & 9 & 217 & 7 & 221 & 7 & 0.29 \\
\hline $\operatorname{VCAM}-1(\mathrm{ng} / \mathrm{ml})$ & 503 & 23 & 554 & 24 & 512 & 22 & 504 & 21 & 0.08 \\
\hline
\end{tabular}

FRAP, ferric-reducing antioxidant potential; SOD, superoxide dismutase; CRP, C-reactive protein; MCP-1, monocyte chemoattractant protein; ICAM-1, intra-cellular adhesion molecule; VCAM-1, vascular cell adhesion molecule.

${ }^{*}$ Comparison of post-intervention (4 weeks) data between groups, using baseline data as a covariate (ANCOVA).

†Data not normally distributed.

second $(1.5-3.7 \mathrm{mg} / \mathrm{l})$ quartiles of baseline CRP concentrations showed associated increases in relative risk for $\mathrm{CHD}$ (2.4-fold) and myocardial infarction or stroke (3.5-fold). The effect size of intervention for CRP in the present study is consistent with and of the same order of magnitude as wholegrain and wholegrain-rich diet interventions which used longer durations $\left(-2.6 \mathrm{mg} / \mathrm{l}\right.$ after 12 weeks ${ }^{(24)}$; $-1.0 \mathrm{mg} / 1$ after 2 years $\left.{ }^{(11)}\right)$, and pharmacological studies using statins which have reported significant lowering of CRP (e.g. -1.22 and $-1.43 \mathrm{mg} / 1$ after 12 weeks $^{(42)}$ ).

Plasma CRP concentration is associated with obesity and is reported to be lowered following weight loss ${ }^{(43)}$. However, we did not find any change in body weight or waist circumference following the intervention, indicating that the decrease in plasma CRP concentration was not owing to weight loss. Changes in CRP may also reflect alterations in plasma lipids, and a meta-analysis of studies using cholesterol-lowering drugs concluded that a $1 \mathrm{mmol} / \mathrm{l}$ decrease in LDL-cholesterol was associated with a $0.89 \mathrm{mg} / 1$ decrease in $\mathrm{CRP}^{(44)}$. We have previously reported a significant decrease in LDL-cholesterol. However, the effect size of intervention on LDL-cholesterol was only $0 \cdot 1 \mathrm{mmol} / \mathrm{l}^{(25)}$, suggesting that the decrease in CRP (effect size of intervention $-1.06 \mathrm{mg} / \mathrm{l}$ ) was much larger than that which could be explained by a lowering in LDLcholesterol alone.

In the present study, we observed a significant lowering in CRP but no change in other inflammatory markers after feeding an aleurone-rich diet for 4 weeks, findings similar to an earlier 12-week intervention using a wholegrain-enriched hypoenergetic diet ${ }^{(24)}$. Production and regulation of CRP takes place predominantly in the liver ${ }^{(45)}$. The change in CRP observed in the present study may therefore reflect alterations in hepatic metabolism resulting from consumption of the aleurone products. This hypothesis is suggested by previously reported data that showed an increase in plasma betaine, and a decrease in plasma homocysteine concentrations, which was attributed to alterations in the activity of the betaine-homocysteine methyltransferase enzyme, found mainly in the liver ${ }^{(25)}$. Plasma homocysteine concentrations have been positively associated with inflammation ${ }^{(46)}$ and betaine, the methyl donor in the betaine-homocysteine methyltransferase pathway, has been hypothesised as an anti-inflammatory nutrient ${ }^{(16)}$. Moreover, betaine also functions as a lipotrope and may have a role as a therapeutic agent in non-alcoholic fatty liver disease ${ }^{(47)}$ and increased CRP concentrations ${ }^{(48)}$.

Although increased betaine status provides a plausible mechanism for the lowering of CRP, other components, such as alkylresorcinols, phytic acid, $\mathrm{Zn}, \mathrm{Mn}$, Cu or ferulic acid may have effects which underlie this anti-inflammatory response ${ }^{(12)}$. However, interactions with the phytic acid present in the aleurone ${ }^{(19)}$ may have decreased the availability of $\mathrm{Zn}, \mathrm{Mn}$ and $\mathrm{Cu}$. Furthermore, previous studies indicate that the availability of ferulic acid may be primarily restricted to free ferulic acid. For example, an in vitro study using a model of the upper gastrointestinal tract found that the bioaccessibility of ferulic acid was less than $1 \%$ of the total ferulic acid in wheat bran, wheat aleurone, and bread with $50 \%$ wheat aleurone ${ }^{(49)}$. Furthermore, a study involving human subjects showed that the postprandial increase in plasma ferulic acid following consumption of $100 \mathrm{~g}$ wheat bran RTE cereal was chiefly owing to the absorption of free ferulic acid, which was less than $2 \%$ of total ferulic acid ${ }^{(50)}$. Free ferulic acid also amounted to less than $2 \%$ of the total in the aleurone products in the present study; this indicates that, despite the large increase in total ferulic acid intake, most of 
this was not available for absorption from the small intestine. However, Vitaglione et al. ${ }^{(51)}$ have suggested that free ferulic acid is released by bacterial activity in the colon, and may be absorbed. Moreover, in contrast to the present results, consumption of $48 \mathrm{~g} / \mathrm{d}$ of wholegrain RTE cereal, or wheat branbased RTE cereals for 3 weeks, resulted in more than 2-fold increases in fasting plasma ferulic acid, which was attributed to the colonic absorption of ferulic acid released through microbial metabolism ${ }^{(52)}$. Taken together, these results indicate that the role of colonic events in the bioavailability of ferulic acid requires further study, and that it may be influenced by factors related to the food matrix, and/or the method of preparation.

Alternatively, it may be that no single anti-inflammatory component is responsible for the lowering of CRP, but rather that the effects are owing to the range of potentially bioactive components, provided by the aleurone products, and which may act independently, or by overlapping or interacting mechanisms. In support of this contention, Gaskins et al. ${ }^{(6)}$ noted that the inverse association between wholegrain intake and CRP was not affected by adjustment for any specific wholegrain nutrient. Moreover, a strong inverse association has been shown between the total antioxidant capacity of the diet and CRP, but not with any single antioxidant compound $^{(53)}$

However, although our results are scientifically plausible, and in keeping with other work, our study was an exploratory analysis with multiple endpoint measures, and thus, in line with a number of similar studies ${ }^{(20,22,23,54,55)}$, Bonferroni corrections were not applied in the data analysis. When a Bonferroni correction is applied $(P<0.002)$, the effect on CRP concentration is no longer significant, and thus it is possible that there is a type 1 error.

In conclusion, this 4-week intervention has shown that the incorporation of aleurone-enriched cereal products into habitual diets results in significantly lower circulating concentrations of the inflammatory marker CRP, an independent risk factor for CVD. However, no changes were found in other markers of inflammation, antioxidant status or endothelial function. These results suggest a putative mechanism underlying the epidemiological evidence for the beneficial effects of wholegrain intake. However, whether the amelioration of CRP levels is attributable to one, a number, or a combination of components in aleurone, or whether the potential antiinflammatory effect contributes to the observed beneficial effects of diets rich in wholegrain, requires further study.

\section{Acknowledgements}

The present study was financially supported by the European Commission in the Communities 6th Framework Programme, project HEALTHGRAIN (FOOD-CT-2005-514008). The authors are solely responsible for the work described in this article, and their opinions are not necessarily those of the European Union. The contributions of the authors were as follows: R. K. P., J. M. W. W., L. L. H., E. M. K., J. J. S. and R. W. W. designed the research; R. K. P., L. L. H. and E. M. K. conducted the research; R. K. P., L. L. H. and E. M. K. analysed the data;
R. K. P., J. M. W. W., L. L. H., E. M. K., J. J. S. and R. W. W. contributed to interpretation of the data; M. J. P. provided statistical advice; R. K. P., J. M. W. W., L. L. H., E. M. K., J. J. S. and R. W. W. wrote the paper; R. K. P. had primary responsibility for the final content. All authors read and approved the final manuscript. There were no conflicts of interest. The authors thank Mr Walter von Reding and Ms Cäcilia Spoerndli, Bühler AG, Switzerland, for the provision of the aleurone and RTE cereals used in this study, Ms Michela Petronio and Mr Giancarlo Riboldi, Barilla G.e R. Fratelli, Italy for the production of the bread products, and Rettenmaier, Germany and Syral, Belgium for the provision of wheat fibre, starch and protein. The authors also thank Professor Peter Shewry and Dr Jane Ward (Centre for Crop Genetic Improvement, Rothamsted Research, UK) for the micronutrient and phenolic analyses of the foods, Professor Vieno Piironen (Department of Food and Environmental Services, University of Helsinki) for tocol analyses of foods, Dr Stephen McClean for his advice and assistance with LC/MS-MS, and Miss Danielle Graham and Mrs Ramandeep Garg for help in carrying out the intervention.

\section{References}

1. Kelly SAM, Summerbell CD, Brynes A, et al. (2007) Wholegrain cereals for coronary heart disease. The Cochrane Database of Systematic Reviews 2007 issue 18, CD005051.

2. Meyer KA, Kushi LH, Jacobs DR, et al. (2000) Carbohydrates, dietary fiber, and incident type 2 diabetes in older women. Am J Clin Nutr 71, 921-930.

3. Schatzkin A, Mouw T, Park Y, et al. (2007) Dietary fiber and whole-grain consumption in relation to colorectal cancer in the NIH-AARP Diet and Health Study. Am J Clin Nutr 85, $1353-1360$.

4. Jacobs DR, Andersen LF \& Blomhoff R (2007) Whole-grain consumption is associated with a reduced risk of noncardiovascular, noncancer death attributed to inflammatory diseases in the Iowa Women's Health Study. Am J Clin Nutr 85, 1606-1614.

5. Masters RC, Liese AD, Haffner SM, et al. (2010) Whole and refined grain intakes are related to inflammatory protein concentrations in human plasma. J Nutr 140, 587-594.

6. Gaskins AJ, Mumford SL, Rovner AJ, et al. (2010) Whole grains are associated with serum concentrations of high sensitivity C-reactive protein among premenopausal women. J Nutr 140, 1669-1676.

7. Lutsey PL, Jacobs DR, Kori S, et al. (2007) Whole grain intake and its cross-sectional association with obesity, insulin resistance, inflammation, diabetes and subclinical CVD: the MESA study. Br J Nutr 98, 397-405.

8. Qi L, Van Dam RM, Liu SM, et al. (2006) Whole-grain, bran, and cereal fiber intakes and markers of systemic inflammation in diabetic women. Diabetes Care 29, 207-211.

9. Jensen MK, Koh-Banerjee P, Franz M, et al. (2006) Whole grains, bran, and germ in relation to homocysteine and markers of glycemic control, lipids, and inflammation. Am J Clin Nutr 83, 275-283.

10. Estruch R, Sacanella E, Badia E, et al. (2004) Different effects of red wine and gin consumption on inflammatory biomarkers of atherosclerosis: a prospective randomized crossover trial - effects of wine on inflammatory markers. Atherosclerosis 175, 117-123. 
11. Esposito K, Marfella R, Ciotola M, et al. (2004) Effect of a Mediterranean-style diet on endothelial dysfunction and markers of vascular inflammation in the metabolic syndrome - a randomized trial. JAMA 292, 1440-1446.

12. Fardet A (2010) New hypotheses for the health-protective mechanisms of whole-grain cereals: what is beyond fibre? Nutr Res Rev 23, 65-134.

13. Lampi AM, Nurmi T, Ollilainen V, et al. (2008) Tocopherols and tocotrienols in wheat genotypes in the HEALTHGRAIN diversity screen. J Agric Food Chem 56, 9716-9721.

14. Welch RW (2010) Nutrient composition and nutritional quality of oats and comparisons with other cereals. In Oats: Chemistry and Technology, 2nd ed., pp. 95-107 [F Webster and P Wood, editors]. St Paul, MN: American Association of Cereal Chemists International.

15. Zeisel SH (2008) Is there a new component of the Mediterranean diet that reduces inflammation? Am J Clin Nutr 87, 277-278.

16. Detopoulou $\mathrm{P}$, Panagiotakos $\mathrm{DB}$, Antonopoulou S, et al. (2008) Dietary choline and betaine intakes in relation to concentrations of inflammatory markers in healthy adults: the ATTICA study. Am J Clin Nutr 87, 424-430.

17. Anson NM, van den Berg R, Havenaar R, et al. (2008) Ferulic acid from aleurone determines the antioxidant potency of wheat grain (Triticum aestivum L.). J Agric Food Chem 56, 5589-5594.

18. Liu LP, Zubik L, Collins FW, et al. (2004) The antiatherogenic potential of oat phenolic compounds. Atherosclerosis $\mathbf{1 7 5}$, 39-49.

19. Buri RC, von Reding W \& Gavin MH (2004) Description and characterization of wheat aleurone. Cereal Food World 49 , 274-282.

20. Enright L \& Slavin J (2010) No effect of 14 day consumption of whole grain diet compared to refined grain diet on antioxidant measures in healthy, young subjects: a pilot study. Nutr J 9, 12-19.

21. Brownlee IA, Moore C, Chatfield M, et al. (2010) Markers of cardiovascular risk are not changed by increased wholegrain intake: the WHOLEheart study, a randomised, controlled dietary intervention. Br J Nutr 104, 125-134.

22. Andersson A, Tengblad S, Karlstrom B, et al. (2007) Wholegrain foods do not affect insulin sensitivity or markers of lipid peroxidation and inflammation in healthy, moderately overweight subjects. J Nutr 137, 1401-1407.

23. Tighe P, Duthie G, Vaughan N, et al. (2010) Effect of increased consumption of whole-grain foods on blood pressure and other cardiovascular risk markers in healthy middle-aged persons: a randomized controlled trial. Am J Clin Nutr 92, 733-740.

24. Katcher HI, Legro RS, Kunselman AR, et al. (2008) The effects of a whole grain-enriched hypocaloric diet on cardiovascular disease risk factors in men and women with metabolic syndrome. Am J Clin Nutr 87, 79-90.

25. Price RK, Keaveney EM, Hamill LL, et al. (2010) Consumption of wheat aleurone-rich foods increases fasting plasma betaine and modestly decreases fasting homocysteine and LDL-cholesterol in adults. J Nutr 140, 2153-2157.

26. Zhao FJ, Su YH, Dunham SJ, et al. (2009) Variation in mineral micronutrient concentrations in grain of wheat lines of diverse origin. J Cereal Sci 49, 290-295.

27. Stroud JL, Zhao FJ, Buchner P, et al. (2010) Impacts of sulphur nutrition on selenium and molybdenum concentrations in wheat grain. $J$ Cereal Sci 52, 111-113.

28. Howarth JR, Parmar S, Jones J, et al. (2008) Co-ordinated expression of amino acid metabolism in response to $\mathrm{N}$ and
S deficiency during wheat grain filling. $J \operatorname{Exp}$ Bot 59, 3675-3689.

29. Li L, Shewry PR \& Ward JL (2008) Phenolic acids in wheat varieties in the HEALTHGRAIN diversity screen. $J$ Agric Food Chem 56, 9732-9739.

30. Price RK, Welch RW, Lee-Manion AM, et al. (2008) Total phenolics and antioxidant potential in plasma and urine of humans after consumption of wheat bran. Cereal Chem $\mathbf{8 5}$, $152-157$.

31. Benzie IFF \& Strain JJ (1996) The ferric reducing ability of plasma (FRAP) as a measure of 'antioxidant power': the FRAP assay. Anal Biochem 239, 70-76.

32. Thurnham DI, Smith E \& Flora PS (1988) Concurrent liquidchromatographic assay of retinol, alpha-tocopherol, betacarotene, alpha-carotene, lyopene, and beta-cryptoxanthin in plasma, with tocopherol acetate as internal standard. Clin Chem 34, 377-381.

33. Matsui Y, Nakamura S, Kondou N, et al. (2007) Liquid chromatography-electrospray ionization-tandem mass spectrometry for simultaneous analysis of chlorogenic acids and their metabolites in human plasma. J Chromatogr B Analyt Technol Biomed Life Sci 858, 96-105.

34. Konishi Y, Zhao ZH \& Shimizu M (2006) Phenolic acids are absorbed from the rat stomach with different absorption rates. J Agric Food Chem 54, 7539-7543.

35. Ridker PM (2003) Clinical application of C-reactive protein for cardiovascular disease detection and prevention. Circulation 107, 363-369.

36. Bassuk SS, Rifai N \& Ridker PM (2004) High-sensitivity C-reactive protein: clinical importance. Curr Probl Cardiol 29, 439-493.

37. Ridker PM, MacFadyen J, Libby P, et al. (2010) Relation of baseline high-sensitivity C-reactive protein level to cardiovascular outcomes with rosuvastatin in the justification for use of statins in prevention: an intervention trial evaluating rosuvastatin (JUPITER). Am J Cardiol 106, 204-209.

38. He LP, Tang XY, Ling WH, et al. (2010) Early C-reactive protein in the prediction of long-term outcomes after acute coronary syndromes: a meta-analysis of longitudinal studies. Heart 96, 339-346.

39. Macy EM, Hayes TE \& Tracy RP (1997) Variability in the measurement of C-reactive protein in healthy subjects: implications for reference intervals and epidemiological applications. Clin Chem 43, 52-58.

40. Danesh J, Wheeler JG, Hirschfield GM, et al. (2004) C-reactive protein and other circulating markers of inflammation in the prediction of coronary heart disease. $N$ Engl J Med 350, 1387-1397.

41. Ridker PM, Buring JE, Shih J, et al. (1998) Prospective study of $\mathrm{C}$-reactive protein and the risk of future cardiovascular events among apparently healthy women. Circulation 98, 731-733.

42. Hanefeld M, Marx N, Pfutzner A, et al. (2007) Antiinflammatory effects of pioglitazone and/or sinivastatin in high cardiovascular risk patients with elevated high sensitivity C-reactive protein - the PIOSTAT study. J Am Coll Cardiol 49, 290-297.

43. Forsythe LKS, Wallace JMW \& Livingstone MBE (2008) Obesity and inflammation: the effects of weight loss. Nutr Res Rev 21, 117-133.

44. Kinlay S (2007) Low-density lipoprotein-dependent and -independent effects of cholesterol-lowering therapies on C-reactive protein - a meta-analysis. J Am Coll Cardiol 49, 2003-2009.

45. Zakynthinos E \& Pappa N (2009) Inflammatory biomarkers in coronary artery disease. $J$ Cardiol 53, 317-333. 
46. Papatheodorou L \& Weiss N (2007) Vascular oxidant stress and inflammation in hyperhomocysteinemia. Antioxid Redox Signal 9, 1941-1958.

47. Abdelmalek MF, Sanderson SO, Angulo P, et al. (2009) Betaine for nonalcoholic fatty liver disease: results of a randomized placebo-controlled trial. Hepatology 50, 1818-1826.

48. Targher G (2006) Relationship between high-sensitivity C-reactive protein levels and liver histology in subjects with non-alcoholic fatty liver disease. J Hepatol 45, 879-881.

49. Anson NM, van den Berg R, Havenaar R, et al. (2009) Bioavailability of ferulic acid is determined by its bioaccessibility. J Cereal Sci 49, 296-300.

50. Kern SM, Bennett RN, Mellon FA, et al. (2003) Absorption of hydroxycinnamates in humans after high-bran cereal consumption. J Agric Food Chem 51, 6050-6055.

51. Vitaglione P, Napolitano A \& Fogliano V (2008) Cereal dietary fibre: a natural functional ingredient to deliver phenolic compounds into the gut. Trends Food Sci Technol 19, 451-463.
52. Costabile A, Klinder A, Fava F, et al. (2008) Whole-grain wheat breakfast cereal has a prebiotic effect on the human gut microbiota: a double-blind, placebo-controlled, crossover study. Br J Nutr 99, 110-120.

53. Brighenti F, Valtuena S, Pellegrini N, et al. (2005) Total antioxidant capacity of the diet is inversely and independently related to plasma concentration of high-sensitivity C-reactive protein in adult Italian subjects. Br J Nutr 93, 619-625.

54. Ross AB, Bruce SJ, Blondel-Lubrano A, et al. (2011) A whole-grain cereal-rich diet increases plasma betaine, and tends to decrease total and LDL-cholesterol compared with a refined-grain diet in healthy subjects. $\mathrm{Br} J \mathrm{Nutr}$ 105, 1492-1502.

55. Giacco R, Clemente G, Cipriano D, et al. (2010) Effects of the regular consumption of wholemeal wheat foods on cardiovascular risk factors in healthy people. Nutr Metab Cardiovasc Dis 20, 186-194. 